\title{
ESTUDIOS
}

\section{EL DERECHO DE PROPIEDAD EN EL PENSAMIENTO DE CARLOS MARX}

Algunos autores han tachado a Marx de contradictorio por la manera como ha concebido y rechazado el derecho de propiedad. Ponen de relieve el que mientras niega el derecho de propiedad privada por una parte, lo está reconociendo implicitamente por ofra al hacer resaltar la tremenda injusticia de una institución social -el capital- que lleva consigo el aumento de bienes de unos miembros de la sociedad a costa del empobrecimiento y miseria de los más. Planteada así la cuestión es innegable la contradicción. Pero ¿está planteada así en la obra de Marx?

Mi intento en este trabajo es comprender a Marx y ver qué es lo que le hace llegar al error de negar la propiedad privada y en qué términos niega la propiedad privada y con qué alcance. Porque, ciertamente, en lo que a este tema se refiere, no hay contradicción en su pensamiento. El error viene por otro concepto, como veremos, y es más profundo.

\section{GESTACION DEL PENSAMIENTO DE MARX SOBRE LA PROPIEDAD}

Bl libro de Carlos Marx La Sagrada Familia es sumamente interesante para conocer cómo se va gastando el pensamiento de este autor en lo que se refiere al derecho de propiedad. Lo escribe en 1844, después de haberse liberado de lo que él llama «alienación religiosa» y «alienación filosófica». No sólo se ha liberado de la Filosofía, sino que en este libro se permite atacar la Crítica crítica formada por Bruno Bauer y su camarilla filosófica, antiguos componentes de la izquierda hegeliana, a la que un día perteneciera el mismo Marx.

En el capitulo IV de esta obra Marx toma la defensa de Proudhon contra la interpretación torcida, a su parecer, de que la Critica crítica habia 
hecho objeto la obra de Protuthon Qu'estwe que la propriété? Con este motivo Marx muestra la evolución de su pensamiento hacia el materialismo dialectico, que, segun algux autor, intuye y se interesa por los problemas de la economía politica, comenzando a germinar en el ideas que más carde desarrolata en El Capital.

Aates de entrar en el estudio que hace Marx de este libro, que muestra haber analizado y asmilado perfectamente, vamos nosotros a hacer un rón pido recorrido por él para comprobar el influjo que las ideas de Proudhon, desarrolladas en esta obra, ejercieron en el pensamiexto de Marx.

Proudhon, en Ou'estwce que la propriétés, se plantea radicalmente el problema de la propiedad, indiscutido en su fundamento hasta entonces. A hacer un análisis de los males que oprimen a la sociedad de su tiempo y de siglos anteriores, busca sus causas y encuentra como fuente de todas ellas la admision como un dogma de fe por los economistas y juristas de todos los tempos del derecho de propiedad.

Dl fin de la obra de Proudhon es nitido y conkesado desde la primera linea: acabar con el concepto de propiedad privada, imposible de sostener, segín él, y causa de los males sociales. La propiedad "c'est le vols, es el robo, nos define en la primera página como contestación a la pregunta que se hace en el risulo.

Desde el comienzo de su obra distingue claramente Proudhon su posición respecto del derecho de propiedad: 10 que va a atacar es el derecho de propiedad, no el de posesion, por al que entiende el derecho de todo hombre a un distrute por igual de los bienes necesarios, sin que nadie pueda privarles de ellos, y con una función social. Esta distinción es muy importante, cono analizaremos después . Admite incluso proudhon el derecho de herencia, no ilimitada, claro esta, dada su mentidad, sino entendida como derecho de opción - no de acumulación- entre varias herencias por parte del heredero.

El método de Proudton es sumamente analitico, Con mucha agudeza, pero con poca profundidad cientifica, intenta probar su tesis: la propiedad privada no cumple el fin de asegurar a todos los hombres el disfrute de los bienes terrenos, $y$ es imposible que lo pueda cumplir. Por tanto es impom sible un derecho basado en ella. Para ello va refutando una por una las razones que los mejores detensores del derecho de propiedad han ido apor tando, especialmente econonistas y juristas. Reduce las razones de éstos a un limite en que lo úniç que probarian es que el derecho de propiedad es igual para todos y que no hay razón que justrigue la desigualad social

1 El mismo lo reconoce cuando dice: $4 . .$. estat doble definicion de la propledad extendida como dominio y como posesion, es de la mayor importaticia; y es necesario tenerla muy ea cuenta si se gutere enterder 10 que vamos a decins, Oewves completes de P. I. Proudhon. Tomo I. Ennes Mlammanion, edior, peris, p. 33. 
existente. En este punto hay que reconocer que sus argumentos tiener Imucha fuerza. Donde ya no tienen tanta es cuando intenta probar que esta igualdad, además, es imposible, y por tanto impositble el derecho de propiedad".

Como se ha podido ver por este brevisimo recorido por la obra de Proudhon Qu'estice que la propriété? lo que en realidad está negando Proudhon, al pretender negax la propiedad privada, es el falso concepto de propiedad privada gestado por el individualismo liberal, defendido en el campo económico por los fisiócratas Adam Strith y sas continuadores, y en el juridico por los juristas de la triunfante Revolución Francesa y el Cón digo Napoleónico. Es ese sentido absoluto de propiedad privada de ilimitado dominio y sin ninguna connotación al bien común, que tan continuamente har condenado los Surnos Pontifices en sus Zunciclicas, desde León XIII a Pí XII.

Es de enorme importancia para enjuiciar la obra de Proudhon recordar la distinción que hace él a comienzo de sal libro entre propiedad privada y derecho de posesión, ya que es fundamental para comprender su actitud y la actitud que tomará después Marx por influjo de Proudhon. Por derecho de posesión entendia el disfrute privado de ciertos bienes, sin que nadie pueda privar al poseedor de ellos, transmisibles incluso por herencia, pero con igualdad y sentido social. Esto que Proudhon llama derecho de posesión, bien entendido y mejor expresado, es lo que se deduce de las Enciclicas de los Sumos Pontifices que es el gerecho de propiedad privada. El que Proudhon llama «dercho de propiedad», con un sentido de absoluto dominio por parte del propietario, sin ningún respeto al bien comín, es el que los Papas en sus Encílicas han condenado como falso. Por lo dicho se ve claramente que Froudhon to niega el genuino concepto de propiedad privada, aunque lo llame de otro modo. Sus diatribas contra lo que se dirigen en realidad es contra el abuso de la propiedad privada.

¿Cómo ve Marx la obra de Proudhon? Es indudable que la trata con simpatía, aunque más tarde, despuess de su ruptura con Proudhon, cambie de parecer y termine por reconocer también êl que Proudhon realmente no negaba la propiedad privada, annque ingenuamente lo presendiera. A pesar de todo, Marz conservará siempre el influjo de las ideas de Proudhoz, que formarán después el sustrato del andilisis económico que hace en su obra cumbre El Capital.

Para Marx el libro de Proudhon constatuye un auténtico acierto. Ve que el carácter distintivo de esta obra «... consiste precisamente en hacer de la cuestión relativa a la esencia de la propiedad privada la cuestión vital de la

2 PROtWHON, a. c., p. 68 
economía politica y de la jurisprudencias ${ }^{3} . \mathrm{Al}$ alabar la actitud de Proudhon se identifica en cierta manera con el pensaniento de éste, y al decir: «La economía políica, que acepta las condiciones de la propiedad privada como condiciones humanas y racionales, se encuentra en contradicción permanente con su condición primordial, la propiedad privada»", nos está dando bien claro a entender que tiene de la propiedad el mismo concepto que Produhon, esto es, una propiedad privada de carácter ilimitado, sin condiciones, no la propiedad privada condicionada al bien social que la doctrina católica considera derecho natural. Por otra parte comienza a aparecer ya en el pensamiento de Marx con toda nitidez, cono veremos por este texto, ese determinismo económico por el que la propiedad privada produce indefectiblemente el elemento antitético que acabará con ella.

Con esta penetración del pensamiento de Proudhon, Marx va encontrando su propio pensamiento y prenuncia ya la idea que será central después en su obra cumbre El Capital: «Proudhon ha ido más lejos. Ha demostrado detalladamente cómo el movimiento del capiral produce la miserias ${ }^{5}$.

Es. más. Comienza a ver en la tímida dialéctica proudhoniana su propia potente dialéctica, y cómo Proudhon inssinúa ya las dos antinomias: propiedad privada o, en otras palabras, capital y proletariado: «El proletariado y la riqueza son antinomias. En cuanto tales constituyen un todo y son dos formas del mundo de la propiedad privada. Se trata de determinar el lugar que ocupan en la antinomia. No basta con decir que son los dos lados de un todo.

La propiedad privada, en cuanto propledad privada o riqueza, se ve forzada a thantenerse ella misma, y por lo tanto a su contrario, el proletariado. Es el aspecto positivo de la antinomia, la propiedad privada que encuentra su satisfacción en sí misma.

Inversamente el proletariado, en cuanto proletariado, se ve forzado a trabajar en su propia supresión y, por consiguiente, en la de la propiedad privada, e. d. en la de la condición que hace de él proletariado. Este es el aspecto negativo de la antinomia, la propiedad privada, hostigada por la inquietud y en vías de disolución»".

La cita ha sido demasiado larga, pero valia la pena de considerarla completa, porque nos muestra ya un Marx de cuerpo entero. Está no sólo esbozada, sino claramente expresada, la concepción social que Marx mantendrá ya a lo largo de toda su vida. Nos muestra sin lugar a dudas su concepción del determinismo económico, que trae consigo como consecuen-

"La Sainte Famille. Oeuvres complètes de Karl Marx. Tomo II. Trad. J. Mohror. Ed. Costes, París 1947, p. 56.

MarX, o. ci, p. 53.

$\because$ lovid., o. c., p. 59 .

6 loid., o. c., p. 60 . 
cia. Farat 13 lucha de clases. Una tesis, propledad privada, y una antítesis, proletariado, que sólo desaparecerán, según el, por el triunto de este útimo, con la fusión en una sintesis fral gue sería el materialismo dialectico co munista que propugna Marr.

Por otra parte, se ve por este wismo texto cómo idenetaca el concepto de propiedad privada con el de riqueza (esto es, capital, entendido ex es sentido individualista liberal de onnimodo domino). No lo identifica, en cambio, con la posesion de los bienes ordinarios de consumo. Ws más, se fija poco después, como hicimos nosotros más armiba, en la distinción que Proudhon hace entre propiedad privada y posesion, y nada tiene gue objerar a este úlimo concepto, sino que, por el contrario, lo defende de la mata interpretacion que de ch hace la Critica critica: "Proudnon nopone, cona 1a critica pretende que hace, 1 a no posesion a la poseston, sino que al antiguo modo de posesion, la propiedad privada, opone la poseśón. Deciara que la posesion tiene wna función socialy " Con esto se ve claramente que ni del ni Proudhon, a quien conenta, concibieron jamás el que la propiedad privada pudiera tener una función Bocial. Whos denen siempre delante de los ojos la concepción de propiedad privada entendida al modo loberal, exclusivamente individualista; pero en thinguna manera la concepcion catolica de propiedad privada con doble funcion: individual a la par gue social. De ahí que lo que Marz propugne hacer desaparecer sea un concepto de propiedad gue también ha condenado la Iglesia er los escritos de los Sumos pontifices.

\section{MADURACION DEL PENSAMTENTO DE MARX SORRF LA PROPTEDAD}

¿Qué piensa Marx del derecho de propiedad? Si nos atenemos a algunos de sus textos más significarvos la primera impresión que sacamos es de gue lo ataca a fondo. Así, cuando leemos en el Manifiesto Comunista, escrito en 1848 en colaboractón con Engels, «La revolución comunista es la más radical ruptura con las relaciones de propiedad tradicionales...»", 0 "Ex. rodos estos movimientos revolucionarios - los comunistas- ponen por delante la cuestión de la propiedad, cualquiera gue sea la forma nás o metros desarrollada que revista, cono la cuestión fundamental del movimienton". $Y$ si escuchamos el tan repetido slogan «abolición de la propiedad privada», también sacado del mismo Manítesto Comunista ", parece aije no deberia guedarnos lugar a duda.

Ibid, o. C., p. 74

\& K. MARx, «Bi Capital.». Manifiesto Comunista. Precios, Sulorios y Gananoios.

Trad. Juan España. Ed. Iborería Berga, Madrid, p. 219.

Ibid., o. c. p. 313 .

to Ibid., o. c., p. 290. 
Por si esto fuera poco, el hecho mismo de enfrentarse con Proudhon, con quien vimos antes identificarse en alguna manera, al darse cuenta de que éste, en realidad no destruye el concepto de propiedad; parece indicarnos que se mantiene en su posición contraria a este concepto.

Assí parece que hay que entenderle cuando dice en Miseria de la Filon sofica: "Como Prondhon subordina el conjunto de estas relaciones econó micas a la noción jurdíca de propiedad, no podia ir más allá de la definicín dada ya por Brissot antes de 1785 en estos mismos términos: la propiedad es el robo" ", por eso concluye que "Como el robo, en cuanto supone violación de la propiedad, presupone la propiedad, Proudhon se embrolla en toda clase de nociones confusas y fantasmagónicas acerca de la verdadera propiedad burguesa» ${ }^{12}$.

Acusa Marx a Proudhon, como veremos por la cita anterior, de que en realidad no ha hecho imposible el concepto de propiedad privada, como pretendía y se gloriaba de haber conseguido.

¿Es justo Marx al afirmar ésto? En realidad, Marx no distingue el dobie concepto de propiedad con que está jugando al acusar a Proudhon y que se va a volver contra él mismo. Proudhon presupone, efectivamente, la propiedad al llamar a ésta robo; pero en realidad lo que está presuponiendo es la propiedad de derecho natural - privada, es cierto, pero con proyección social-, y a lo que llama robo es a la propiedad privada, concebida al modo individualista liberal, propiedad de dominio abscluto, condenada tambiér por los Sumos Pontifices en sus Encíclicas. Marx, a su vez, cae en el mismo defecto que censura en Proudhon al confundir en un solo concepto esas dos mismas nociones. A ambos les faltó conocer el concepto de propiedad, derecho natural, que tiene la doctrina católica. Concepto más que esbozado por los Santos Padres y por la tradición escolástica, aunque todavía no tan precisado como se haria después en las encíclicas sociales, la primera de las cuales, la Rerum Novarum de S. S. León XIII, se publicó años después de la muerte de Marx.

Basándose en los textos anteriores, o en otros equivalentes de K. Marx y de su inseparable amigo y colaborador Engels, algunos autores tratan de refutar esta negación del derecho de propiedad con argumentos ad hominem, apoyándose en los escritos mismos de Marx, intentando probar que se contradice. Así, por ejemplo, Charles Mac Fadden dice: «El comunismo defiende que el trabajo personal del obrero le da derecho a lo que ha producido o a un valor equivalente. En una palabra; el principio básico de la teoría comunista de la plusvalia es de por sí una defensa de la propiedad privada. Es un ataque al capitalismo porque priva al hombre de lo que ha adquirido, con todo derecho, por su trabajo personal, ${ }^{13}$.

\footnotetext{
1. K. Marx, Misere de la Philosophie. Ed. Costes, p. 216.

12 Ibid., o. c., p. 217.

13. CRARzes MAC Fadoen, La Filosofía del Comunismo. Ed. S. Ever R. Cuesta. Valladolid, 1949, p. 324 .
} 
Efectivamente. Trodos los capitulos de El Coptal de Marx, en los que an concienzuda y dramáticaneate se exponen las teortas de la pluswalla y sus complementarias del trabajo cooperativo y del cjército industrial de reserva, son otros tantos gritos de protesta contra un estado de inizisticia. Y si tenen fuerza es precisamente por eso, porque denuncian cóno se está arrebatando al trabajador incuanente gran parte de lo que es suyo. Lo cual no tendria sentido si no estuviera latentemente reconocido el derecho de hropiedad.

Pero tha negado Mara derecho del trabajo a distrutar de lo producido por él? En otros terminos. du negado Marz el derecho de propiedad de los bienes de consumo, que a esto se teducirian los obtenidos del trabajo persona? En el Manifiesto Comunista nos dac: «... Lo que el obrero se apropia por su actividad es estrictamente lo que necesita para entretener stu misera existencia y para reproducila. No gueremos de ninguna matuera aboliz esta apropinción personat de los productos del trabajo, indispensable a la conservacion y a la reproduccion de la vida humana: esta apropiación no deja ningin beneficio liguido que confiera poder sobre el rabajo de otron ${ }^{14}$.

Así, pues, no cabe duda de que K. Marx no niega el derecho de prom piedad de los bienes uindispensables a la conservación y a la reproducción de la vida humana». Con lo cual admite la objeción de que reamente reconoce el derecho de propiedad. Lo que tenía que haber logrado el autor antes citado es demostrar que realmente existe una contradicción en admirir el mismo derecho de propiedad, que afirma en wnas de sus obras y rechaza en otras.

Siendo esto así, cabe la pregunta: liuego se contradice Marx al negar por una parte el derecho de propiedad que admite por otra?

Para que Mark se contradijera sería necesario probar que en todos los pasajes citados está tratando del mismo derecho de propiedad y en el mismo sentido. Entonces si que habrí una auténtica contradicción. Pero jes ésto lo que ocurre en la realidad?

Esto nos introduce en el punto central de nuestro trabajo, clave para entender el verdadero pensamiento de Mart acerca de la propiedad.

¿Qué es lo que K. Marx entiende por propiedad privada, cuando la niega en unos pasajes de stus obras, mientras la está afinmando más o menos veladamente en otros?

Hay unos párrafos en el Manifiesto Comunista, definitivos para conocer el verdadero pensamiento de Marx en la materia que tratamos y por los que los autores que, en general, han tratado del comunismo han pasado sin valorarlos como merecen. Son los siguientes:

1.4 K. MARx, Manifiesto Cornunista, o, c., p. 291. 
《El carácter distintwo del comunismo no es la abolicion de la propiedad en general, sino la abolicion de la propiedad burguesas ${ }^{35}$.

Teste otro;

\&egún esto, la propiedad privada actual, la propiedad burguesa, es la álima y la más perfecta expresion del modo de producción y de apropia ción basacio sobre los antagonismos de las clases, sobre la explotación de los unos por los otros.

Lu esce sentido, los comunistas pueden resumir su teoría en esta fómula única: «abolición de la propiedad privada» "

Desentrañemos el contenido de estas expresiones porque nos va a dar mucha luz en asurito que tratamos.

Los dos textos se explican mutuameate; por eso los tenemos que estudiar juthamente. Primeramente veamos lo que dice: «fn este sentodo los commnistas pueden resumir su teoria en esta formula única: abolicion de la pro piedad privada. ' toué sentido es ese de gue habla? Sin lugar a dudas de la propledad burguesa, de la gue ha hablado en el texpo anterior, Pero antes de penetrar en el conocimiento de lo que es la propiedad burguesa tipemonos bien en la distinción que hace del concepto de propiedad privada. Lo entiende en bos sentidos. El primero, propiedad privado general, cuya abolición no pretende el comunismo. X el segundo, propiedad burguesa, que es propiamente contra la que ditige sus tiros.

¿Qué eatiende Marx por propiedad privada general? La respuesta a esta pregunta nos la da Marx en el parrafo que hemos citado más arriba del Mantifiesto Comunista (véase cia no 14 ): chtiende por propiedad privada general la «apropiación personal de los productos del trabajo, indispensables a la conservacion y a la reproducción de la vida humanas. O sea, lo que hoy llamariamos bienes de consumo.

¿ labras que nos dan la pista para conocer también qué entiende Marz por propiedad burguesa. Dice: «... esta apropiación - habla de los bienes de consumo- no deja ningún beneficio líquido que confiera poder sobre el trabajo de otros. Con esto nos da a entender claramente que, para él, propiedad burguesa es la que da beneficio liquido y poder a su poseedor sabre el trabajo de otro. Lo que hoy podríamos llamar propiedad de los medios de producción.

¿Por qué propugna Marx la abolición de la propiedad burguesa, esto es, la propiedad de los medios de producción?

Este es ya un segundo paso que damos para llegar al fondo de la cuestión. Mas si queremos conocer con nitidez el pensamiento de Marx tenemos

is Ibid, o. c c, p. 290 .

to K. MARx. Manifiesto Comunista, o. c., p. 290. 
todavía que hacer una doble matización en esa que al llama propiedad burguesa y que condena en bloque.

La propiedad burguesa se puede considerat desde dos ángulos: en cuanto que es propiedad privadia y en cuanto que lo es de los medios de producción, aungue no se pueden separar en ella estos dos elementos porque sería destruir el concepto.

En cuanto propiedad privada, ¿por gué condena Matx este tupo de prom piedad, cuando mas arriba hemos visto que la aprueba cuando se trata del producto del trabajo personal? Es mas, contrapone la una at otro ${ }^{37}$. No cabe duda de que Marx, cuando condena la propiedad privada burguesa, tiene delante de los ojos el concepto individualista y liberal burgues de sin época; la propiedad de dominio inmitado, sin responsabulidad sociat, que ya indicamos y uego veremos más charamente que condena también la Iglesia. Esto se confima, sobre todo, cuando leemos en el Manifiesto Com munista: «E capital no es (..) una fuerza personal: es una herra sociat. Por consecuencia, cuando un capital sea transformado en propiedad comín, perteneciente a todos los miembros de wa sociedad, no sera una propiedad personal que se haya cambiado en propiedad común. Sólo habrá cambiado el carácter social de la propiedad. Perdeń su carácter de clase» ${ }^{*}$.

Se ve claramente por las palabras anteriores cómo Marz ha intúdo que el capial tiene que tener una proyección social y que no puede ser exclu. sivamente personal, como ya desde antiguo lo tiene presente la doctrina católica. ILástima que Marx no conociera esta doctrina y sólo tuviera presente como cristianismo la iglesia luterana de la primera mitad del siglo XWX. escayolada en moldes hegelianos! Esto le hubiera hecho ver algo que se le pasó por alto, como nos da a entender en el púrrato cíado: que son compatibles función social del capta con propiedad privada. el, en cambio, al no ver este nexo de unión, los juzga inconciliables, y por no admitir wara propiedad privada de sentido puramente personal, sin proyección social, niega toda propiedad privada de medios de producción.

Falta considerar el segundo ángulo de la propiedad burguesa, en cuanto es propiedad de los medios de producción. Ya queda adelantada la respuesta en parte al aclanar, cono hicimos, el concepto de propiedad privada. Pero hay ciertos matices enta que la hacen particularmente odiosa a Marz: el que sea instrumento para la explotación del trabajador. Esta idea aparece continuamente en El Capital. Es el tema de la obra, que se deduce especialmente de las teorías de la plusvalía y del trabajo cooperativo. Así dice en el capitulo XXIX: «Los medios de producción y de subsistencia no se transforman en capital sino cuando se utilizan como medios de explotar

17 世En su forma actual, la propiedad se mueve entre estos dos terminos antinó micos: capitat y trabajo. Manifiesto Comunista, o. c., p. 291.

18 Manifiesto Comunista, o. c., p. 291. 
y dominar al trabajon ". Wh error de Marx ha consistido en considerar cono esencia misma de la propiedad privada de los thedios de producción - llevar consigo fatalmente la explotación del proletariado, algo gue ni sir quiera ella misma puede exitar porgue esta esencialmente entrañado al sism tema, como se ve por estas palabras del capitulo XXTV de El Caprial: «SI el proletariado no es más que una máquina gue produce plusvalia, el capitalista es también una máquina que capitaliza esa plusvalià " Y no consideró que todo eso no era atribuble swo an abuso de la propiedad. Aungue, como siempre, tiene delane de los ojos el concepto individualista de la propiedad, que realmente es ma abuso de la misma.

Todavía cabe plantearnos esta pregunta: al propugnar Marz la abolicion de la propiedad privada de los medios de produccion, 10 hace radicalmente por una razón de orden juridico que excluye el derecho natural o simplemente se trata de ung consecuencia de su sistema dialéctico materialista?

Inducirian a pensar lo primero sus palabras textuales aishadas ya citadas a lo largo de ste trabajo. Sin embargo, sstudiando el sisterna de Marz en su conjunto se ve que no tiene la menor precupacion de orden juridico. El derecho lo sitúa en la esfera de la superestructura de la sociedad, como algo alienado, llamado a desaparecer. Por tanto, mal podia llamar en su ayuda para apoyar su negación del derecho de propiedad razones de orden jurídico que él empieza por no admitir.

La contestación a la pregunta anterio habrá que hacefla por tanto en el segundo sentido, esto es, que la negación de la propiedad es una consecuencia de su sistema materialista diatectico.

En efecto, él concibe el capital (para el es equivalente esta palabra a propiedad de los medios de producción) como un momento necesaric para el progreso de la humanidad hacia su etapa definitiva del comunismo, meta que no se logrará sino por la destrucción de ese mismo capital, una vez terminado su cometido. Ya que para éste cumpla la misión social que le corresponde es necesario arrancar de manos de los particulares los medios de producción y transformarlos ex propiedad común.

En el capítulo XXVII de El Capital nos da a entender Marx muy clam ramente esta concepción, al descubrimos el proceso de gestación y acumum lación del capital. Nos dice en él que la propiedad privada de la producción es la que está constituída por los elementos de trabajo de los particulares ${ }^{2 x}$, y cambia según pertenezcan al trabajador 0 wo. En el primer caso hace del trabajador un hombre libre, hábil y diestro ${ }^{2: 2}$. La propieclad está dividida y es igual para todos. Sin embargo, es una saciedad en mediana, sin nom

19 El Capital, o. c., p. 261.

20 Ibid., o. c., p. 212 .

Ibid., o. c., p. 256.

Ibid., o. c. p. 256. 
table progreso, ya que quedar exchúdas en ella las ventajas del trabaio cooperativo ${ }^{23}$.

Cuando los medios de producción no pertenecen al trabajador, comienza a operar el acrecentamiento por la piusvalía y por concentración aparece el capital ${ }^{2}$, con sus terribles consecuencias, ya que, seguin Marx., «... en el fondo de la acumulación primitiva y de su formación histónica está la expropiación del productor inmediato, la desaparicion de la propiedad fundada en el trabaio personal de su poseedor ${ }^{23}$. Por eso exclama: "La propiedad privada, basada en el trabajo personal: esa propiedad que se adhiere, por decirlo ast, al trabajador aislado y autonomo a las condiciones exteriones del trabajo ha sido suplantada por la propiedad privada capitalista, fundada en 1 a explotación del trabajo ajeno, en el régimen de salario ${ }^{25}$.

Y es esa propiedad capiralista la que acaba con la propiedad privada del trabajador independiente, como había dicho también anteriomente en el Manifiesto Comunista, cuando acusa a los burguieses: «Pero er vuestra som ciedad la propiedad privada está abolida para las nueve décimas partes de sus tniembros. Precisamenze porque no existe para esas nueve décimas partes existe para vosotros» ${ }^{2 \pi}$.

Al llegar a este punto, un lector lógico y no conocedor de la concepción marxista quedará desconcerado. Efectivamente, de todo este proceso histórico seguido en la gestación del capital parece deducirse que la solución a la alienación social y económica está en una vuelta a ese estado primitivo e idilico de propiedad privada de los medios de producción por el propio trabajador, previa corrección de los abusos cometidos por la propiedad burguesa: Y no, como propugna Marx, supuimir la propiedad privada de los medios de producción y suplantarlos por una explotación socializada de los bienes en común. Ya que esto es llevar a témino la inicua expropiación del trabajador iniciada por el capitalismo.

Sin embargo, Marx no ve en todo esto más que un movimiento necesario y fatal de progreso, por el que la humanidad ha tenido que pasar en su evolución perfectiva hacia el comunismo.

¿Por qué Marx propone esta solución, única que se compagina con el progreso de la humanidad?

En el capitulo XXVII de El Capital, antes analizado, se ve muy charamente esta vuelta del pensamiento de Marx. En medio de los males que consigo había traído la burguesía, una cosa buena habia descubierto, aunque para aprovecharse egoisticamente de ella: el valor del trabajo social y coope-

\footnotetext{
Ibid., o. c., p. 257

Ibiat., o. c., p. 257.

Ibid, o. c, p. 256.

Ibid., o, c., p. 257.

Manifiesto Comunista, o. c., p. 292.
} 
rativo. Una sociedad no puede progresar sino con esa organización del trabajo: por eso habia progresado la burguesia y por eso Marx no desea una vuelta al trabajo individual que haria perder estas conquistas y beneficios para la sociedad 28. Esto mismo expresa también en el Manifiesto Comunista cuando dice: «El capital no es (...) una fuerza personal: es una fuerza socials (ver cita n. ${ }^{\circ}$ 18). Por eso, al tener la propiedad burguesa una función socializadora de la producción, ve en ella Marx un factor de progreso. Para que esta fuerza social cumpla su misión enteramente, sin los periucios que en ella ve Marx, es por lo que propugna su socialización total, facilitada por el hecho de la acumulación del capital en pocas manos.

El error de Marx ha consistido en no concebir que la propiedad privada, sin dejar de ser privada, podria cumplir su función social. El concepto extremadamente individualista de propiedad, concepto falso, como veremos, que encontró en su tiempo vigente en el mundo burgués, le hizo inclinarse, al buscar una solución al problema, al otro extremo de comunización de los medios de producción, sin estudiar la posibilidad de que la verdadera som lución pudiera estar en el centro: propiedad privada de los medios de producción podada de abusos y cumpliendo la función social que le corresponde, como propugna la Iglesia.

Como vimos en el estudio anterior del capitulo XXVIII de El Capiant, Marx reconocía las ventajas de la propiedad privada individual, cómo hacia a los hombres libres, hábiles e iguales. La ofuscación vino al no concebir que ese tipo de propiedad pudiera progresar. El vió que el progreso lo habia trá́do consigo el capital al socializar el trabajo, tras una división racional del mismo, y hacerlo cooperativo. Pero zho estaba la solución en que ese mismo trabajo libre se asociara y esos capitales pequeños, individuales, se asociaran tambiérn? Todos vemos cómo pequeños capitales unidos forman esas poderosísimas sociedadas anónimas, capaces de emprender las mayores empresas. Era problema de redistribución de la riqueza. Esto no lo vio Marx, por eso no dí́ con la verdadera y justa solucion.

La concepción de Marz, en lo que se refiere al derecho de propiedad, no es sino una consecuencia de su sistema dialéctico materialista. La propiedad no es sino un momento de antítesis ${ }^{29}$, puente entre la tesis, comunismo natural primitivo, y la síntesis el comunismo materialista dialéctico. La propiedad privada de loc medios de producción, dentro de este esquerna filosofico, está determinada por un proceso fatal, por su propia naturaleza, a producir su contrario, el proletariado, cuya liberación está ligada a la destrucción de este tipo de propiedad. (Ver nota n. ${ }^{\circ} 10$.)

28 El Capital, o. c., p. 258.

y9 F. Engels expresa esto con toda claridad en Anti-During, p. 169. También trata este punto en L'Origine de la famille, de la propriéré privée é de l'Etat. Ed. Cortes. Paris. 
Resumiendo, podemos concretar el pensamiento de Marx acerca del derecho de propiedad en los puntos siguientes:

1. Distinción fundamental entre la propiedad privada general (de los bienes de consumo) y propiedad burguesa (de los bienes de producción).

2. Admite la primeraj rechaza la segunda.

3. Entiende la propiedad privada en el sentido absoluto del indivim dualismo liberal, y en este sentido propone su abolición.

4." Rechaza la propiedad privada de los medios de producción, entendida como en el punto anterior, en cuanto se contradice a sí trisma, al generar con el proletariado su propia destrucción, y en cuanto comporta una fatal explotación del proletariado. Prescinde de la propiedad privada, enrendida como derecho natural, cuyo problema no se plantea,

5. Los medios de producción tienen una función social que cumplir. De ahi que la propiedad de los mismos tenga que ser social y que los beneficios que proporciona reviertan en la sociedad.

6. No sospechó que los medios de producción pudieran conservar sux función social en manos privadas; de ahí el que exija su posesión en común.

Enjuiciando el resumen anterior podemos comprobar que Marx sólo se aparta de la concepción católica del derecho de propiedad, como derecho natural secundario, en el 5." punto, por el error de visión que consignamos en el 6. Ya que de que la propiedad tenga una función social concluye ilícitamente que tiene que ser toda ella social.

Todo esto nos hace ver que una refutación de Marx, que le acuse de negar en general el derecho de propiedad, será injusta. Sólo será acertada cuando refute el que la propiedad de los bienes de producción haya de ser exclusivamente de la sociedad como tal, porque ahí es donde está el error.

En realidad, como dice el P. Herri Chambre, "... para Marx no hay propiedad ni derecho de propiedad en sentido absoluto. Hay formas de propiedad, de apropiación y de tégimen de bienes que son contingentes» ${ }^{30}$.

RAIMUNDO VILLAGRASA, S. I.

30 Henra Chamare. Le Marxisme en Union Sonterique. Ed. du Seuil. Paris, 1955, p. 129. 
